\title{
Natural health wellness: an effective prevention of DKD
}

\author{
Narisa Futrakul ${ }^{* *}$ and Prasit Futrakul ${ }^{2}$ \\ ${ }^{1}$ Department of Physiology, Faculty of Medicine, King Chulalongkorn Memorial Hospital, Chulalongkorn University, Thailand \\ ${ }^{2}$ Fellow in Academy of Science, The Royal Society of Thailand, Bhumirajanagarindra, Kidney Institute, Thailand
}

\begin{abstract}
Renal microvascular disease and diabetic kidney disease develop at the early course of diabetes mellitus. Under common practice, vasodilator treatment at DKD stage 3 or later fails to correct renal ischemia, due to the altered vascular homeostasis associated with an impaired angiogenesis. In addition, there is also elevated antiangiogenic factors in the blood that induce a progressive renal microvascular disease.

Under current vision, therapeutic strategy should be implemented at the early DKD stages (1 and 2). Vasodilator treatment at this early stage would enhance the renal perfusion, and restore the renal, function. Such treatment in conjunction with the patient's self-sufficiency philosophy under natural health wellness regime, would minimize the development of end-stage renal disease in diabetes mellitus.
\end{abstract}

\section{Introduction}

A National Health Wellness is the Wisdom of Lord Buddha stating that 'A person with the HOT AND COLD BALANCE' state would be away from an illness [1]. A HOT AND COLD BALANCE is the balance between autonomic nervous system and neuroendocrine system, which in view of medical practice, would be expressed as the balance of vascular function. With respect to the structure and function of nephron, it consists of 2 crucial compartments namely (1) glomerulus which is blood vessel supplying to the (2) tubulointerstitium. Both compartments are integratedly functional as indicated as follow.

\section{A normal nephronal unit}

Normally, a normal renal plasma flow $\left(600 \mathrm{ml} / \mathrm{min} / 1.73 \mathrm{~m}^{2}\right)$ after filtrating about $120 \mathrm{ml} / \mathrm{min} / 1.73 \mathrm{~m}^{2}$ as glomerular filtration rate, the remaining blood would pass through the efferent arteriole to become peritubular capillary flow $\left(480 \mathrm{ml} / \mathrm{min} / 1.73 \mathrm{~m}^{2}\right)$ to supply the tubulointerstitium [2]. It contains nutrients such as carbohydrate, lipid, protein to be metabolized by mitochondria to yield a high energy ATP production. In addition, it also produces intracellular toxins such as $\mathrm{CO}_{2}$, oxygen radicals and heat. In order to maintain the 'HOT AND COLD BALANCE, state the toxic products have to be eradicated by means of blood and or urine such as (1) $\mathrm{CO}_{2}$ is carried to the lung to exchange for $\mathrm{O}_{2}$, (2) the blood carries antioxidants to neutralize the oxygen radicals (3) heat is carried out from intracellular compartment via blood or urine. Therefore, these mechanisms associated with an adequate blood supply or normal vascular function would assist the kidney cell to maintain 'HOT AND COLD BALANCE' state - an healthy condition.

\section{Diabetic kidney disease}

In diabetes mellitus, there are a variety of circulating toxins namely oxidative stress, glycation end products, lipid, sugar, hypertension etc that remain elevated in the circulation, in particular sugar which cannot enter into the cell due to the altered insulin metabolism. These toxins induce vascular injury and initially damage the endothelial cell resulting in its detachment from the vascular wall [3]. Indeed, circulating endothelial cells have been encountered to be elevated in the blood in the early course of diabetes mellitus prior to the onset of microalbuminuria [4]. This alters the negatively charged surface (anticoagulant property) of the vascular wall to become positively charged surface (procoagulant property). Platelet aggregation is frequently observed in the peripheral blood smear and an increased platelet consumption has been indicated by a shortened platelet-half-life [5-8]. Due to the loss of endothelial cell lining of the renal blood vessel which is the source of nitric oxide production, the renal microvascular disease becomes provasoconstrictive, and renal ischemia is induced. The intrarenal hemodynamic study reveals a reduction in renal plasma flow, as well as a reduction in peritubular capillary flow in the early course of diabetes mellitus, during the stage of normoalbuminuria [9]. Further study during microalbuminuria, there is a greater reduction in renal plasma flow and peritubular capillary flow [10]. The metabolism of nutrient in mitochondria in diabetic patient is shifted to lipid and protein. In the present of renal ischemia, it produces less ATP and instead a greater amount of intracellular toxic products such as oxygen radical, acid, heat. In this regard, the removal of toxins is inadequate. Heat accumulation in the cell is suppressed by the process of water entering the cell, which eventually causes cell swelling. The structure and function of cell becomes disfiguring. Such structural charge would impair the production of ATP in the mitochondria, and subsequently develop mitochondrial failure. There is an attempt to activate the reflex autonomic nervous system to contract the cell for toxin removal, without a successful result. The progressive accumulation of intracellular toxins alters the 'HOT AND COLD BALANCE' state and eventually induces

${ }^{\star}$ Correspondence to: Narisa Futrakul MD, Ph.D, Department of Physiology, Faculty of Medicine, King Chulalongkorn Memorial Hospital, Bangkok,10400, Thailand, Tel: +66 2256 4951; Fax: +66 256 4911; E-mail: fmednft@yahoo.com

Key words: national health wellness, diabetic kidney disease, vascular homeostasis, renal microvascular disease, diagnostic markers

Received: November 14, 2019; Accepted: November 22, 2019; Published: November 26, 2019 
tubulointerstitial injury and fibrosis. The reflex autonomic nervous system activation would further contract the renal microvascular vessel which results in a greater reduction of renal plasma flow and peritubular capillary flow. It has been demonstrated that the reduction in peritubular capillary flow correlates with the magnitude of tubulointerstitial fibrosis [11]. In this regard, the presence of normal peritubular capillary flow is usually associated with a normal tubulointerstitial structure. The reduction in peritubular capillary flow precedes the development of tubulointerstitial fibrosis. A greater reduction in peritubular capillary flow induces a higher degree of tubulointerstitial fibrosis.

\section{A current status of therapeutic strategy in diabetic kidney disease}

Under common practice, physicians have generally followed the recommendation of National Kidney Foundation and KDOGI, to recognize the diabetic kidney disease when there is microalbuminuria present [12,13]. This simply implies that the earliest recognition of diabetic kidney disease is DKD stage 3. In general, therapeutic prevention of DKD usually initiates at DKD stage 3 . The best result following this therapeutic regime is simply slow the renal disease progression, but is unable to restore the renal function [10]. To address to this crucial issue, the study in vascular homeostasis in diabetic patients associated with DKD stage 3 and up revealed a defective angiogenesis resulting in an impaired nitric oxide production, as well as an impaired endothelial cell proliferation [14-24]. This would explain the therapeutic resistance to vasodilator treatment and the inability to improve the renal ischemia observed in general practice. Furthermore, there is also an elevated level of antiangiogenic factors namely vascular endothelial growth factor acceptor 2 (VEGFR2) and angiopoietin 2, which induce vascular smooth muscle cell proliferation, and endothelial cell proliferation inhibition, respectively $[3,25]$. Taken together, they induce a progressive renal microvascular disease, as well as a progressive renal ischemia, as the disease severity progresses toward end-stage renal disease.

\section{Current concept of therapeutic strategy}

The preceding information renders support that the therapeutic strategy of DKD should be implemented earlier than DKD stage 3. In this regard, it requires sensitive diagnostic markers to early recognize DKD stage 1,2. It has been noted that the determination of serum creatinine and microalbuminuria are not sensitive enough to screen for this early stage, therefore, eGFR and creatinine clearance should be replaced as a screening biomarker [26,27]. However, due to the limitation of glomerular hyperfiltration state observed in DKD stage 1 ; the eGFR or creatinine clearance would be overestimated. Other biomarker such as a fractional excretion of magnesium (FE Mg) has been applied to screen for early renal function impairment with a rather satisfactory result. Theoretically, magnesium is detached from the tubular cell during the process of tubular cell injury. An increase in urinary magnesium is reflected by an abnormally elevated FE Mg. It has been demonstrated that FE Mg correlates directly with the magnitude of tubulointerstitial fibrosis $[28,29]$, and negatively correlates with the peritubular capillary flow reduction [30].

\section{Vascular Biomarkers}

Inasmuch as the mechanism of diabetic kidney disease is associated with the development of renal microvascular disease and renal ischemia originating in the early course of diabetes mellitus, vascular biomarkers would be an alternative biomarker to indirectly reflect the stage of diabetic kidney disease. Recently, angiotensin converting enzyme (ACE), endothelin-1 (ET-1) endostatin have been abnormally elevated during normoalbuminuria, and progressively increased as disease progresses toward microalbuminuria [27]. Endostatin is recognized as antiangiogenic factor the elevation of endostatin inversely correlated with the reduction in GFR [3]. Therefore, vascular biomarkers would be usefully sensitive to screen for early renal microvascular disease, as well as early diabetic kidney disease.

\section{National Health Wellness As an Effective Prevention of DKD}

The National Health Wellness has its main therapeutic target to rely mainly on the patient's self-sufficiency state to minimize the toxin production in the body, as well as to remove the toxin production in the body, as well as to remove the toxin out of the circulation and cell $[31,32]$. To serve for this purpose, the successful outcome is dependent on

1. A habit of consuming a balanced health diet. Since diabetic kidney patients usually accumulated heat in the cell, diet should contain more vegetables, non - sweetened fruit, less carbohydrate, protein and no trans containing fat. It should be noted that the amount of toxins produced is dependent on the amount and frequency of food consumption. A regular breakfast and lunch, and a little dinner or avoidance of dinner is preferable.

2. Resting. A fasting period of 8-10 hours would be appropriated for the repairing process of the cell injury and allow cell to recover for the process of toxin removal. This issue has recently emphasized by the 2016 Noble Prize Laureate Professor Yoshinori Ohsumi who described the crucial role of 'Autophagy' in the cell.

3. Exercise. This practice is beneficial not only to improve the body circulation, but also to enhance the process of toxin removal such as through the bowel, sweat, and other organs etc.

4. Meditation. This genuine practice would facilitate the body and mindset calmness. It would minimize the body metabolism resulting in minimizing toxin production. It would allow the release of endorphin and growth hormone to facilitate the cell repair and recycling, whilst suppress the undesirable hormones such as adrenaline or catecholamine which antagonizes the repairing and recycling ability of the cells.

Taken together, all the practical steps would allow the cell to maintain the 'HOT AND COLD BALANCE' state and thus keep oneself away from disease.

\section{A Correction of Renal Ischemia and Restoration of Renal Function}

With the assistance of sensitive diagnostic markers to screen for early DKD stage, vasodilator administration, in conjunction with the patient's self-sufficiency philosophy would be able to enhance renal plasma flow, peritubular capillary flow, as well as an enhancement of glomerular filtration rate in early DKD stage. Indeed, a significant enhancement of renal perfusion, and renal function has recently been documented in early DKD stage associated with normoalbuminuria $[33,34]$.

\section{Disclosure Statement}

We declare there is no conflict of interest in the content of the article. 


\section{Funding}

We appreciate the support of The National Research Council of Thailand, Chulalongkorn University, The Royal Society of Thailand, and Bhumirajanagarindra Kidney Institute.

\section{References}

1. Klajon J (2016) Self-sufficiency philosophy. Health Decode Book. Usa Prine Bangkok, Thailand 1: 20-23.

2. Futrakul N, Sila-asna M, Futrakul P (2007) Therapeutic strategy towards renal restoration in chronic kidney disease. Asian Biomedicine 1: 33-44. [Crossref]

3. Futrakul N, Futrakul P (2017) Biomarker for early renal microvascular and diabetic kidney diseases. Renal Fail 39: 505-511. [Crossref]

4. Futrakul N, Vongthavarawat V, Sirisalipotch S, Chairatanarat T, Futrakul P, et al. (2005) Tubular dysfunction and hemodynamic alteration in normoalbuminuric type 2 diabetes. Clin Hemorheol Microcirc 32: 59-65. [Crossref]

5. Wiggins RC (1989) Role of coagulation in glomerular and vascular disease. In Massry SG, Glassock RJ (eds). Textbook of Nephrology 1: 572-577.

6. Schambelan M, Blake S, Srew J, Bens M, Nivez MP, et al. (1985) Increased prostaglandin production by glomeruli isolated from rats with streptozotocin - induced diabetes mellitus. J Clin Invest 75: 404-412. [Crossref]

7. George CRP, Slichter SL, Quadracci LJ, Striker GE, Harker LA (1974) A kinetic evaluation of hemostasis in renal disease. N Engl J Med 293: 1111:1115. [Crossref]

8. Futrakul P, Posyschinda M, Mitrakul C (1978) Focal sclerosing glomerulonephritis: A kinetic evaluation of hemostasis and the effect of anticoagulation therapy: A controlled study. Clin Nephrol 10: 180-186. [Crossref]

9. Futrakul N, Butthep P, Vongthavarawat V, Futrakul P, Sirisalipoch S, et al. (2006) Early detection of endothelial injury and dysfunction in conjunction with correction of hemodynamic maladjustment can effectively restore renal function in type 2 diabetic nephropathy. Clin Hemorheol Microcirc 34: 373-381. [Crossref]

10. Futrakul N, Futrakul P (2013) Vascular response to vasodilator treatment in microalbuminuric diabetic kidney disease. World J Nephrol 2: 125-128. [Crossref]

11. Futrakul N, Yenrudi S, Sensirivatana R, Watana D, Laohapaibul A, et al. (2000) Perutubular capillary flow determines tubulointerstitial disease in idiopathic nephrotic syndrome. Ren Fail 22: 329-335. [Crossref]

12. National Kidney Foundation (2012) KDOQI clinical practice guidelines and clinical practice recommendation for diabetes and chronic kidney disease. Am J Kidney Dis 49: S12-S154. [Crossref]

13. Lin CH, Chang YC, Chuang LM (2016) Early detection od diabetic kidney disease: Present limitations and future perspectives. World J Diabetes 257: 290-301. [Crossref]

14. Futrakul N, Butthep P, Futrakul P (2009) Altered vascular homeostasis in type 2 diabetic nephropathy. Ren Fail 31: 207-210. [Crossref]

15. Bortoloso E, Del Prete D, Vestre MD, Gambaro G, Saller A, et al. (2004) Quantitative and qualitative changes in vascular endothelial growth factor gene expression in glomeruli of patient with type 2 diabetes. European J Endocrinol 150: 799-807. [Crossref]
16. Loomans CJ, de Koning EJ, Staal FJ, Rookmaaker MB, Verseyden C, et al. (2004) Endothelial progenitor cell dysfunction \& novel concept in the pathogenesis of vascular complications of type 1 diabetes. Diabetes 53: 195-199. [Crossref]

17. Tepper OH, Galiano RD, Capla JM, Kalka C, Gagne PJ, et al. (2002) Human endothelial progenitor cells from type 2 diabetes exhibit impaired proliferation, adhesion and incorporation into vascular structures. Circulation 106: 2781-2786. [Crossref]

18. Woolf AS, Gnudi L, Long DA (2009) Roles of angiopoietins in kidney development and disease. J Am Soc Nephrol 20: 239-244. [Crossref]

19. Lindenmeyer MT, Kretzier M, Bouchesst A, Berra S, Yasuda Y, et al. (2007) Interstitia vascular rarefaction and reduced VEGF-A expression in human diabetic nephropathy. J Am Soc Nephrol 18: 1763-1776. [Crossref]

20. Li J, Bertram JF (2010) Review: endothelial-myofibroblast transition, a new player in diabetic renal fibrosis. Nephrology 15: 507-512. [Crossref]

21. Ranastei Y, Suzuki D, Uchave G, Toyoda M, Katoh T, et al. (2005) Vascular endothelial growth factor gene expression is correlated with glomerular neovascularization in human diabetic nephropathy. Am J Kidney Dis 45: 288-294. [Crossref]

22. Nakagawa T, Kosugi T, Haneda M, Rivard CJ, Long DA (2009) Abnormal angiogenesis in diabetic nephropathy. Diabetes 58: 1471-1478. [Crossref]

23. Futrakul N, Futrakul P (2011) Vascular homeostasis and angiogenesis determine therapeutic effectiveness in type 2 diabetes. Int J Vasc Med p. 971524. [Crossref]

24. Wacharasindhu S, Rugpolmuang R, Roonghiranwat T, Supornsilchai V, Sahakitrungruang T, et al. (2013) Preliminary study of renal hemodynamic alteration in early childhood diabetes mellitus. Ren Fail 35: 98-100. [Crossref]

25. Carlsson AC, Ostgren CJ, Lanne T, Larsson A, Nystrom FH, et al. (2016) The association between endostatin and kidney disease and mortality in patients with type 2 diabetes. Diab Metab 42: 351-357. [Crossref]

26. Perrona RD, Madias NE, Levey AS (1992) Serum creatinine as an index of renal function: new insights into old concepts. Clin Chem 38: 1933-1953. [Crossref]

27. Futrakul N, Cheisuriya P, Retanabanangkoon K, Futrakul P (2013) Microvascular dysfunction in normotensive, normoalbuminuric, normo - or hyperfiltrate type 2 diabetes. Ren Fail 35: 1191-1192. [Crossref]

28. Futrakul P, Yenrusi S, Futrakul N, Sensirivatana R, Kingwatanakul P, et al. (1999) Tubular function and tubulointerstitial disease. Am J Kidney Dis 33: 886-891. [Crossref]

29. Deekajorndech T (2007) A biomarker for detecting early tubulointerstitial disease and ischemia in glomerulonephropathy. Ren Fail 29: 1013-1017. [Crossref]

30. Futrakul N, Futrakul P (2011) Indices indicating early renal microvascular disease in diabetes. The Open Biomarkers $J$ 4:18-20.

31. Futrakul N, Futrakul P (2011) Diabetic nephropathy: Current concept of therapeutic strategy toward self-sufficiency. $J$ Nephrol Therapeutic 52: 1-10.

32. Futrakul N, Futrakul P (2017) A self-sufficiency philosophy for non-communicable disease control. J Clin Nephrol Ren Care 3: 33.

33. Futrakul N, Kulapatana O, Futrakul P, Chavanakul A, Deekajorndech T (2011) Enhanced peritubular capillary flow and renal functioin can be accomplished in normoalbuminuric type 2 diabetic nephropathy. Ren Fail 33: 312-315. [Crossref]

34. Ritt M, Ott C, Raff U, Schneider MP, Schuster I, et al. (2009) Renal vascular endothelia function in hypertensive patients with type 2 diabetes mellitus. Am J Kidney Dis 53: 281-289. [Crossref]

Copyright: (C2019 Futrakul N. This is an open-access article distributed under the terms of the Creative Commons Attribution License, which permits unrestricted use, distribution, and reproduction in any medium, provided the original author and source are credited. 